\title{
Perfil dos acidentes com aranhas no estado de Goiás no período de 2007 a 2011
}

\author{
Profile of arachnid accidents in the State of Goias, Brazil, between 2007 and 2011
}

\author{
Ana Flávia de Paula Guerra ${ }^{1}$, Flávia Cruz dos Reis ${ }^{1}$, Anita de Moura Pessoa ${ }^{2}$, Nelson Jorge da Silva Jr ${ }^{3}$ \\ ${ }^{1}$ Graduandas da Faculdade de Medicina da Pontifícia Universidade Católica de Goiás (PUC Goiás). Goiânia, GO. \\ ${ }^{2}$ Doutoranda em Biotecnologia e Biodiversidade. Rede em Associação Ampla. Goiânia, GO. \\ ${ }^{3}$ Doutor em Zoologia pela Brigham Young University. Professor titular e Coordenador do Programa de Mestrado em Ciências Ambientais e Saúde \\ da PUC Goiás. Goiânia, GO.
}

\section{RESUMO}

Objetivos: Descrever os aspectos epidemiológicos e clínicos dos acidentes com aranhas reportados ao Centro de Informações Toxicológicas do Estado de Goiás. Comparar e contrastar os dados de descrição e avaliação do quadro clínico e uso do soro específico com as recomendações do Ministério da Saúde e da literatura médica.

Métodos: Para a coleta de dados foram utilizadas as fichas de notificação do Centro de Informações Toxicológicas de Goiás. Os dados sobre a expansão urbana foram obtidos no Instituto Brasileiro de Geografia e Estatística e através de imagens de satélite Landsat.

Resultados: No período estudado, o araneísmo no estado de Goiás correspondeu a $15,91 \%$ dos acidentes com artrópodes peçonhentos, totalizando 659 casos. As duas microrregiões com maior ocorrência foram Goiânia, com 305 casos (46,28\%) e Entorno de Brasília, com 69 $(10,47 \%)$. Houve um acometimento maior dentro da faixa etária de 20 a 39 anos. A região mais comum da picada foi o pé. O intervalo entre acidente e atendimento, na maioria dos casos, foi de uma a três horas. A dor foi o sintoma mais prevalente, podendo estar associada a edema, hiperemia e parestesia que, juntamente com sintomas vagais, determinaram a gravidade do acidente. Em 214 casos foi usada soroterapia, sendo informado o tipo de soro em $83,17 \%$ dos mesmos. Houve uso de número excessivo de ampolas de soro de acordo com as recomendações do Ministério da Saúde em 98,87\% dos casos em que o dado pôde ser levantado. Dos casos informados, 89,37\% evoluíram para a cura. Os dados não indicam o gênero da aranha que foi agente causal dos acidentes.

ConclusÕes: Os resultados indicam que a prevalência do araneísmo está ligada ao processo de expansão urbana. O tratamento foi em geral satisfatório, com alto índice de cura e inexistência de óbitos. Houve uso desnecessário de soro e de um número incorreto de ampolas em muitos casos. Os dados sugerem um distanciamento das recomendações do Ministério da Saúde, que possui protocolos claros, desde a identificação da aranha até o uso de soro conforme a gravidade do caso.

DESCRITORES: ARACNIDISMO; ARANEÍSMO; PICADURAS DE ARANHAS; EPIDEMIOLOGIA.

\section{ABSTRACT}

Aims: To describe the epidemiological and clinical aspects of the spider accidents reported at the Center for Toxicological Information of the State of Goiás. To compare and contrast the data of description and evaluation of the clinical picture and use of specific serum with the recommendations of the Ministry of Health and the medical literature.

Methods: The data were collected using the report notes of the Center for Toxicological Information of the State of Goiás. The data on the urban expansion were obtained at the Brazilian Institute of Geography and Statistics and through Landsat satellite images.

Results: In the period of this study the spider accidents in the State of Goiás represented 15,91\% of the accidents with venomous arthropods, with a total of 659 cases. The two micro regions with the highest occurrence of cases were Goiânia, with 305 cases $(46,28 \%)$ and the surroundings of Brasília, with 69 cases (10,47\%). There was a higher incidence in the 20 to 39 years age group. The most common region of accident was the foot. The time interval between accident and first medical care, in the majority of the cases, was between one and three hours. Pain was the prevailing symptom, which might be associated with edema, hyperemia and paresthesia, which together with vagal symptoms determine the gravity of the accident. In 214 cases serum therapy was used, and the type of serum was informed in $83.17 \%$. There was use of excessive number of serum ampoules according to the Ministry of Health recommendations in $98,87 \%$ of the cases in which these data could be recovered. Among the notified cases, $89,37 \%$ evolved to cure. The data did not indicate the spider genus that caused the accidents.

Conclusion: These results indicate that the prevalence of spider accidents is linked to the urban expansion. In general the treatment was satisfactory, with high rate of cure and absence of deaths. There was an unnecessary use of serum and an incorrect number of ampoules in many cases. These data suggest a detachment from the recommendations of the Ministry of Health, which possess clear protocols, from identification of the spider to use of serum according to the gravity of the case.

KEY WORDS: ARACHNIDISM; ARANEISM; SPIDER ACCIDENTS; EPIDEMIOLOGY 


\section{INTRODUÇÃO}

Os acidentes causados por aranhas, denominados de araneísmo, apesar de relativamente negligenciados, são considerados como um problema de saúde pública, em especial nas regiões tropicais do mundo. ${ }^{1}$ No Brasil, são registrados em média 23.000 acidentes por ano, principalmente nos Estados do Paraná, Santa Catarina e São Paulo. ${ }^{2}$

A Organização Mundial de Saúde (OMS) considera que apenas quatro gêneros de aranhas possuem espécies que podem causar envenenamento grave no ser humano: Latrodectus (conhecida como "viúva negra"), Loxosceles (conhecida como "aranha marrom") e Phoneutria (conhecida como "armadeira"), da família Araneomorphae; e Atrax, da família Mygalomorphae. Em Goiás, o foneutrismo (acidente com Phoneutria), é o principal responsável pelos acidentes com aranhas. ${ }^{2}$ Nele predominam as manifestações locais, sendo o sintoma mais frequente a dor imediata, com intensidade variável, que pode se irradiar até a raiz do membro afetado.

Os acidentes causados por aranhas ocorrem durante todo o ano, com um aumento em época de acasalamento, período no qual elas estão mais ativas. Na maioria dos casos, esses acidentes ocorrem em ambientes intra ou peridomiciliares, estando relacionados ao ato de calçar e vestir, ou ao manuseio de legumes e frutas. ${ }^{3,4}$ Algumas atitudes podem diminuir os índices de araneísmo e, consequentemente, a morbidade e a mortalidade, como por exemplo, medidas que evitem a proliferação e realizem o controle desses animais em áreas urbanas, por meio da identificação das áreas prioritárias através do mapeamento das ocorrências. $^{5}$

Apesar do número de acidentes por animais peçonhentos ser elevado no país e de existirem sistemas nacionais de informação, como o Sistema de Informação de Agravos de Notificação (SINAN) que contempla o registro desse tipo de agravo à saúde, essas informações não são suficientes para delinear a dimensão real desse problema, tornando-se necessária a revitalização do sistema de informação e o incentivo de estudos sobre esse tipo de agravo, aliado à proposição de novas formas de análise midiatizada por fatores ambientais e socioeconômicos. ${ }^{6}$

O presente trabalho apresenta o perfil do araneísmo no Estado de Goiás no período de 2007 a 2011, investigado por meio da análise de fichas de notificação de acidentes depositadas no Centro de Informações Toxicológicas (CIT) do Estado de Goiás. Esta análise teve por objetivo o conhecimento do quadro clínico mais prevalente apresentado pelo paciente e a necessidade ou não do uso de soroterapia, contrastando esses achados com as recomendações preconizadas para esse tipo de acidente pelo Ministério da Saúde e pela literatura médica específica.

\section{MÉTODOS}

O estudo, aprovado pelo Comitê de Ética em Pesquisa da Pontifícia Universidade Católica de Goiás sob o parecer consubstanciado de número 544.723, compreendeu todos os casos registrados de acidentes por aranhas entre 2007 e 2011 no Estado de Goiás, tendo como referência o CIT na capital, Goiânia.

Os dados epidemiológicos oficiais foram obtidos a partir do sistema eletrônico do SINAN. Das fichas de Investigação de Acidentes por Animais Peçonhentos, foram coletadas todas as características epidemiológicas e clínicas do acidente. Para o mapeamento da área em estudo, foram delimitadas as áreas urbanas do estado de Goiás através da interpretação de imagens de satélite e dispostos por meio de mapa. Para execução de tais tarefas utilizou-se o software ArcGIS 9.3. ${ }^{7}$ Os dados demográficos e estatísticos gerais da área de abrangência foram obtidos do Instituto Brasileiro de Geografia e Estatística (IBGE), através de sua base de dados eletrônica. ${ }^{8}$

As variáveis observadas foram tratadas em forma de tabelas e gráficos. A taxa de incidência foi calculada de acordo com as orientações da Organização PanAmericana de Saúde, tendo como base uma população de 100.000 habitantes (casos $\times 100.000$ /população). ${ }^{9}$

Para avaliação dos procedimentos terapêuticos nos casos notificados utilizaram-se as recomendações contidas no Manual de Vigilância Epidemiológica de 2009 do Ministério da Saúde (MS) ${ }^{10}$ (Quadro 1).

\section{RESULTADOS}

De acordo com o SINAN, ocorreram 776 casos de acidentes com aranhas no estado de Goiás no período de 2007 a 2011, porém nesse mesmo período, nas fichas de notificação arquivadas no CIT, constam 659 casos. O agente causal dos acidentes não foi informado. Conforme a metodologia proposta, serão analisados neste estudo somente os casos do CIT, que foram distribuídos em 123 municípios e 18 microrregiões. As duas microrregiões com maior ocorrência foram Goiânia, com 305 casos $(46,28 \%)$ e Entorno de Brasília, com 69 (10,47\%) (Figura 1). 
Quadro 1. Número

de ampolas de soros antiaracnídico e antiloxoscélico indicado para cada tipo e gravidade do acidente, conforma as diretrizes do Ministério da Saúde ${ }^{12}$

\begin{tabular}{|c|c|c|c|}
\hline Acidente & Tipo de soro & Gravidade & $\begin{array}{l}\text { Número } \\
\text { de ampolas }\end{array}$ \\
\hline \multirow{3}{*}{ Foneutrismo } & \multirow{3}{*}{ Antiaracnidico (SAA) } & Leve: dor local, edema, eritema, sudorese, piloreção & - \\
\hline & & $\begin{array}{l}\text { Moderado: dor local intensa, sudorese, vômitos } \\
\text { ocasionais, agitação psicomotora, hipertensão arterial }\end{array}$ & 2 a 4 \\
\hline & & $\begin{array}{l}\text { Grave: sudorese profunda, sialloreia, vômitos profusos, } \\
\text { priaprismo, choque, edema pulmonar agudo }\end{array}$ & 5 a 10 \\
\hline \multirow{3}{*}{ Loxoscelismo } & \multirow{3}{*}{$\begin{array}{l}\text { Antiloxoscélico (SALox) } \\
\text { ou Antiaracnidico (SAA) }\end{array}$} & $\begin{array}{l}\text { Leve: aranha identificada, lesão incaracterística, ausência } \\
\text { de comprometimento sistêmico }\end{array}$ & - \\
\hline & & $\begin{array}{l}\text { Moderado: independemente da identificação do agente, } \\
\text { lesão sugestiva ou característica, manifestações sistêmicas } \\
\text { inespecíficas (exantema, febre), ausência de hemólise }\end{array}$ & 5 \\
\hline & & $\begin{array}{l}\text { Grave: lesão característica, manifestações clinicas e/ou } \\
\text { evidências laboratoriais de hemólise intravascular }\end{array}$ & 10 \\
\hline
\end{tabular}

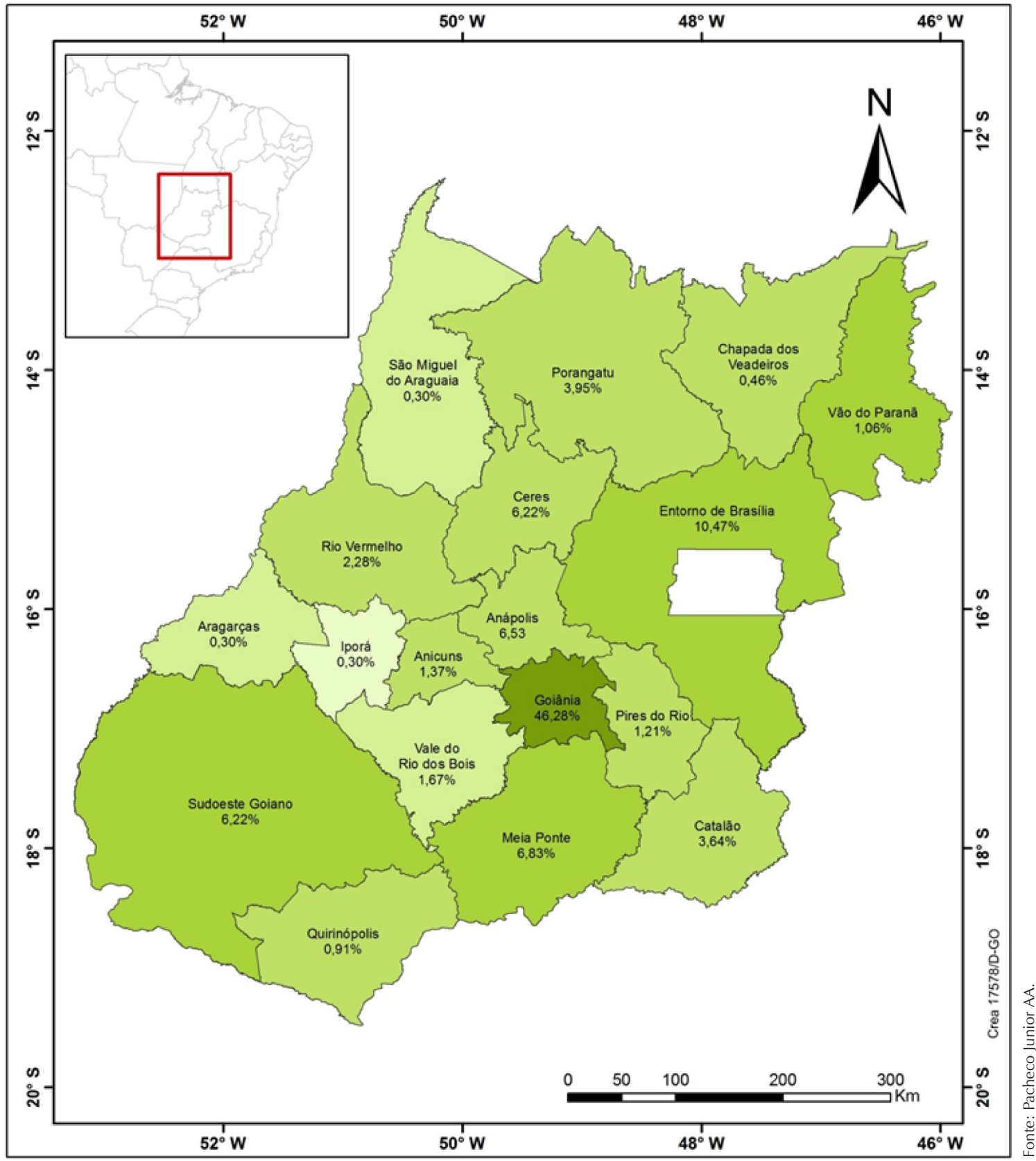

Figura 1. Distribuição dos acidentes com aranhas no estado de Goiás, no período de 2007 a 2011. 


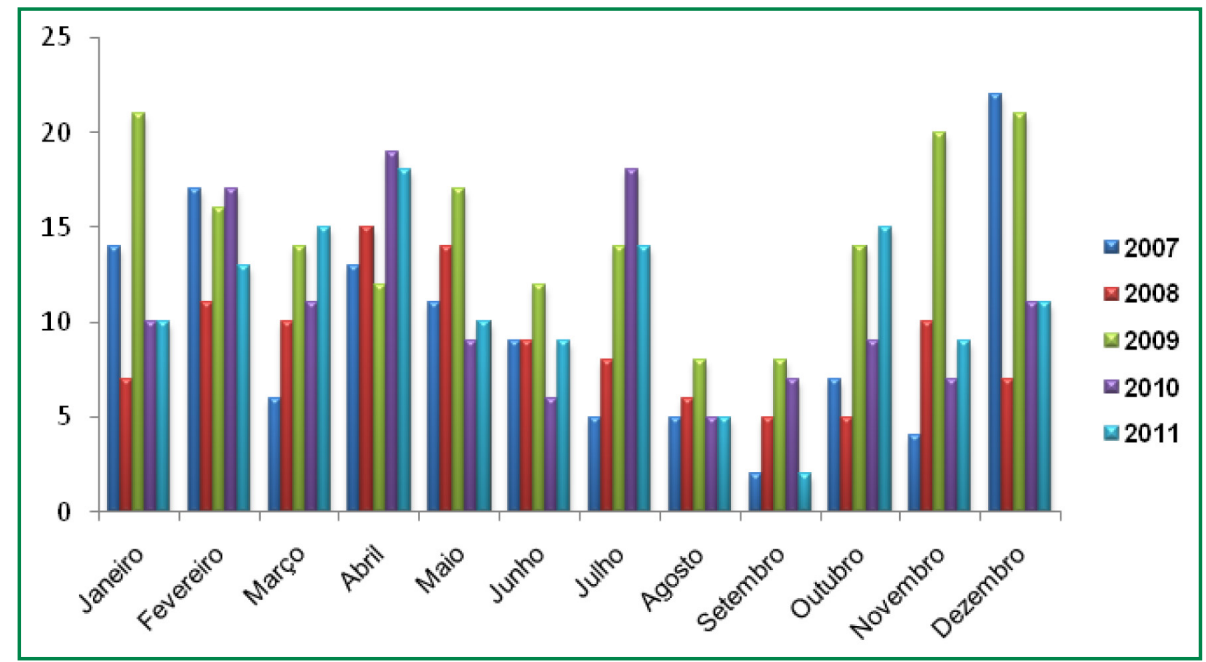

Figura 2. Sazonalidade dos acidentes com aranhas no período de 2007 a 2011 no estado de Goiás.
Dentre os 659 casos analisados, 478 (72,53\%) foram informados nas notificações como sendo de intensidade leve, 131 (19,88\%) como moderados, 12 (1,82\%) como graves e $38(5,77 \%)$ não foram classificados quanto à gravidade. Os acidentes apresentaram uma relação discreta com a sazonalidade, com muitas variações. $\mathrm{O}$ ano de 2009 apresentou maior número na maioria dos meses, comparado aos outros anos, com total de 177 casos (26,85\%). Quanto aos meses, fevereiro e abril apresentaram a maior concentração de araneísmo, com $74(11,22 \%)$ e 77 casos $(11,68 \%)$, respectivamente. Agosto foi o mês com menor número de notificações com 29 casos (4,40\%) (Figura 2).

Quanto ao gênero, $364(55,23 \%)$ dos acidentes foram com indivíduos do gênero masculino e 267 (40,51\%) com indivíduos do gênero feminino, o que representa uma diferença de $15 \%$. Em quatro casos $(0,60 \%)$, não foi informado o gênero do paciente. Os intervalos de faixa etária mais expressivos foram os de 20 a 29 anos $(n=131 ; 20,62 \%)$ e o de 30 a 39 anos $(\mathrm{n}=104 ; 16,38 \%)$. Em terceiro lugar foram relatados $84(12,74 \%)$ casos em pacientes de um a nove anos. Em 24 (3,64\%) casos não foram informadas as idades dos acidentados.

A Tabela 1 detalha a região anatômica atingida no acidente com aranhas, sendo a mais frequente o pé, que correspondeu a $20,33 \%$ dos casos.

Quanto ao tempo entre acidente e atendimento, em 155 notificações $(23,53 \%)$ o intervalo foi inferior a uma hora; em $186(28,22 \%)$ foi de uma a três horas; em $97(14,72 \%)$ de três a seis horas; em 42 (6,38\%) de seis a 12 horas; em $40(6,06 \%)$ de 12 a 24 horas; e em 62 casos $(9,41 \%)$ o atendimento ocorreu no período acima de 24 horas. Em 77 notificações (11,68\%) o tempo transcorrido não foi informado.
Tabela 1. Região anatômica atingida nos acidentes com aranhas no estado de Goiás entre 2007 e 2011

\begin{tabular}{|l|c|}
\hline \multicolumn{1}{|c|}{ Região Anatômica } & N \\
\hline Pé & 134 \\
\hline Dedo* & 108 \\
\hline Mão & 92 \\
\hline Artelho & 78 \\
\hline Perna & 42 \\
\hline Braço & 33 \\
\hline Antebraço & 29 \\
\hline Coxa & 22 \\
\hline Tronco & 17 \\
\hline Cabeça & 16 \\
\hline Peito e Costas & 10 \\
\hline Peito & 8 \\
\hline Dedo da mão & 6 \\
\hline Costas & 2 \\
\hline Cabeça e Braço & 1 \\
\hline Dedo e Coxa & 1 \\
\hline Dedo e Perna & 1 \\
\hline Glúteo & 1 \\
\hline Pé e Perna & 1 \\
\hline Pênis & 1 \\
\hline Tornozelo & 1 \\
\hline Não informado & 55 \\
\hline Total & 659 \\
\hline
\end{tabular}

* Não especificado se mão ou pé.

A Tabela 2 descreve os principais sintomas relatados nas fichas e apresentadas de acordo com a gravidade dos casos. Quanto aos sintomas locais, nos casos leves a dor de caráter não específico, se local ou não, aparece como principal manifestação, enquanto 
que nos casos moderados e graves, foi predominante a dor local associada a edema. Para as manifestações sistêmicas, sintomas como diarreia, náuseas e vômitos, denominados de vagais, tiveram maior prevalência.

O tempo de coagulação foi realizado em $46(6,98 \%)$ pacientes. Desses, quatro $(8,69 \%)$ apresentaram resultados alterados e $42(91,30 \%)$ normais. Dentre o total de casos, apenas para um $(0,15 \%)$ paciente classificado como moderado foi relatado à presença de infecção secundária.
Em 214 pacientes foi utilizado soro como tratamento, distribuído nos tipos antibotrópico (AB), antiescorpiônico (SAesc) e antiaracnídico (SAAr). Do total, em apenas 178 (83,17\%) fichas foi informado o tipo de soro. Observa-se que a utilização do soro em alguns casos não seguiu as diretrizes do MS, ocorrendo como ausência de classificação do quadro clinico, administração em casos de gravidade leve e uso incorreto de quantidade de ampolas (Tabela 3).

Tabela 2. Principais sintomas (locais e sistêmicos) dos acidentes com aranhas notificados pelo Centro de Informações Toxicológicas no estado de Goiás, no período de 2007 a 2011

\begin{tabular}{|c|c|c|c|c|c|c|}
\hline \multirow{2}{*}{ Sintomas } & \multicolumn{4}{|c|}{ Grau de gravidade } & \multirow[b]{2}{*}{$\mathbf{N}$} & \multirow[b]{2}{*}{$\%$} \\
\hline & Leve & Moderado & Grave & NC & & \\
\hline \multicolumn{7}{|l|}{ Sintomatologia local } \\
\hline Dor local de caráter não especifico & 161 & 28 & 2 & 11 & 202 & 36,13 \\
\hline Dor local e Edema & 143 & 54 & 0 & 11 & 208 & 37,2 \\
\hline Dor local e Parestesia & 20 & 3 & 1 & 1 & 25 & 4,47 \\
\hline Dor local, Edema e Hiperemia & 27 & 20 & 1 & 2 & 50 & 8,94 \\
\hline Dor local e Hiperemia & 28 & 5 & 2 & 0 & 35 & 6,26 \\
\hline Prurido & 9 & 1 & 0 & 1 & 11 & 1,96 \\
\hline Equimose & 13 & 8 & 3 & 4 & 28 & 5 \\
\hline \multicolumn{7}{|l|}{ Sintomatologia sistêmica } \\
\hline Diarreia, Náusea e Vômito (vagais) & 20 & 16 & 1 & 0 & 37 & 53,62 \\
\hline Cefaleia & 11 & 0 & 0 & 0 & 11 & 15,94 \\
\hline Febre & 5 & 0 & 1 & 2 & 8 & 11,59 \\
\hline Turvação Visual & 2 & 2 & 0 & 0 & 4 & 5,8 \\
\hline Comprometimento Renal & 2 & 1 & 1 & 0 & 4 & 5,8 \\
\hline Taquicardia & 1 & 4 & 0 & 0 & 5 & 7,25 \\
\hline
\end{tabular}

$\mathrm{NC}=$ gravidade não classificada.

Tabela 3. Tipo de soro, número de ampolas, e número de pacientes de acordo com a classificação de gravidade

\begin{tabular}{|c|c|c|c|c|c|}
\hline \multirow[t]{2}{*}{ Gravidade do caso } & \multicolumn{4}{|c|}{$\begin{array}{l}\text { Número de pacientes distribuído conforme gravidade do caso } \\
\text { e número de ampolas usadas em cada caso }\end{array}$} & \multirow{2}{*}{$\begin{array}{l}\text { Número total de pacientes } \\
\text { em cada classificação } \\
\text { de gravidade }\end{array}$} \\
\hline & 1 a 3 ampolas & 4 a 6 ampolas & 7 a 10 ampolas & NI & \\
\hline \multicolumn{6}{|l|}{ SAAr } \\
\hline Leve & $40^{*}$ & 27 & 3 & 1 & 71 \\
\hline Moderado & 21 & 57 & $14^{*}$ & 1 & 93 \\
\hline Grave & 1 & 5 & 5 & 0 & 11 \\
\hline Não classificado & 1 & 0 & 0 & 0 & 1 \\
\hline \multicolumn{6}{|l|}{$\mathbf{A B}$} \\
\hline Leve & 1 & 0 & 0 & 0 & 1 \\
\hline \multicolumn{6}{|l|}{ SAesc } \\
\hline Moderado & 1 & 0 & 0 & 0 & 1 \\
\hline \multicolumn{6}{|l|}{ Não informado tipo de soro } \\
\hline Leve & 6 & 3 & 1 & 6 & 16 \\
\hline Moderado & 9 & 9 & 0 & 0 & 18 \\
\hline Não classificado & 0 & 2 & 0 & 0 & 2 \\
\hline Total & 80 & 103 & 23 & 8 & 214 \\
\hline
\end{tabular}

$\mathrm{NI}=$ número de ampolas não informado.

* Número de ampolas excessivo para a gravidade do caso. 
Do total de casos notificados ao CIT, $589(89,37 \%)$ evoluíram para a cura total. Os outros $70(10,62 \%)$ não tiveram a evolução informada. A taxa de incidência para o estado de Goiás foi de 10,97 acidentes/100.000 habitantes. Para o município de Goiânia, o qual notificou maior número de casos, a incidência foi de 14,40 acidentes/100.000 habitantes. Em nenhuma das notificações foi identificado o gênero da aranha como agente causal.

\section{DISCUSSÃO}

A notificação de 776 casos de araneísmo para o Estado de Goiás no SINAN apresenta uma discrepância com os dados do CIT, que no mesmo período recebeu notificações de 659 acidentes com aranhas. A diferença de 117 casos pode estar relacionada a diversos fatores envolvidos no processo de coleta e transmissão dos dados. Para Chagas et al., ${ }^{11}$ apesar de o número de acidentes por animais peçonhentos ser elevado no país e de dispormos de sistemas nacionais de informação, que contemplam o registro desses acidentes, ainda há um grande problema na consolidação desses dados. A microrregião de Goiânia apresentou o maior número de ocorrências, sendo a cidade que apresenta maior área urbana, o que reforça a hipótese de urbanização dos acidentes com aranhas.

Quanto à sazonalidade, os acidentes aracnídeos não apresentaram relação com os períodos de chuva ou seca, pois os acidentes ocorreram o ano todo, o que corrobora com outros autores. Para Lucas, ${ }^{12}$ os quatro primeiros meses do ano são o período no qual ocorre a maioria dos acidentes, isto porque coincide com o período de chuvas, que desaloja os animais, forçando a procura de abrigos em locais secos, como as residências. Castro et al. ${ }^{5}$ relatam que nos meses de outubro a abril ocorre a maior incidência dos acidentes, seguindo os padrões conhecidos da literatura, de maior atividade dos aracnídeos nos meses mais quentes, relacionados à maior locomoção e ao ciclo reprodutivo. Segundo o MS, a distribuição dos acidentes é praticamente uniforme ao longo do ano nos estados da região Centro Oeste, sendo esse padrão compatível com os resultados encontrados neste estudo. ${ }^{10}$

Com relação ao gênero/sexo, houve uma diferença de apenas 15\%, sugerindo que os acidentes com aranhas possam não estar somente relacionados com a atividade laboral. A faixa etária mais acometida segue sendo de 20 a 39 anos, o que está de acordo com os dados do MS, correspondendo ao período de maior produtividade. Entretanto, foi expressivo também o número de casos com crianças entre um e nove anos de idade. ${ }^{10}$ Estudos comprovam que acidentes com crianças ocorrem em razão da abundância de aranhas do gênero Loxosceles no interior das residências, permitindo o maior contato com esses animais. Ao serem comprimidas contra o corpo humano, as picadas ocorrem como forma de defesa. ${ }^{13,14}$

Com relação ao local da picada, os membros inferiores como os mais acometidos apoiam os resultados encontrados por Andrade et al., ${ }^{15}$ nos quais a extremidade inferior, sobretudo os pés, constituíram os locais de maior ocorrência das picadas. Regiões pouco comuns, como nádegas, face, região pubiana e pescoço, sugerem uma associação entre a ocorrência destes acidentes e atividades de lazer ou o ato de se vestir, reportando novamente à domiciliação destes aracnídeos.

Observa-se que a busca por atendimento em unidade de saúde deu-se em um período menor que três horas após o acidente com o aracnídeo, sendo essa atitude associada a melhor prognóstico e menor risco de complicações, culminando em menores taxas de mortalidade. Essa busca por atendimento rápido na maioria dos casos pode ser justificada pela dor local provocada pelo veneno. ${ }^{12}$

A maioria dos casos classificados como leves, com acometimento local e evolução geralmente benigna para adultos, sem necessidade de soroterapia, corrobora com outros autores. ${ }^{10}$ A presença de dor local foi evidenciada na maioria dos casos e, segundo o MS, a dor pode ser de maior ou menor intensidade, dependendo da espécie de aranha. Após algumas horas, tornam-se evidentes dor, eritema e edema na região da picada, além de eventualmente ocorrerem equimose ou bolhas. ${ }^{12}$ No que se refere às manifestações sistêmicas, foram prevalentes sintomas como diarreia, náuseas e vômitos, seguidos por mal estar, cefaleia, febre e exantema, quadro considerado comum para esse tipo de acidente. ${ }^{12}$

Frente a um paciente vítima de picada por aranha, a solicitação de exames adicionais segue a clínica do paciente. Os exames mais solicitados são eletrólitos, principalmente nas manifestações gastrointestinais; enzimas cardíacas e eletrocardiograma em manifestações cardiovasculares, como arritmia; e radiografia de tórax quando os pacientes apresentam quadro respiratório. ${ }^{15}$ Exames que testam a coagulação na maioria das vezes não são necessários, a menos que haja manifestações hemorrágicas, o que não é comum no araneísmo. Nos casos aqui analisados, foi realizado tempo de coagulação em apenas $7 \%$ dos casos notificados, sendo que mais de $90 \%$ mostraramse normais. 
Dentre as complicações, foi relatado apenas um caso com infecção secundária e um com edema agudo de pulmão. Nesse último caso, além do paciente estar em um grupo de risco, pois apresentava três anos de idade, a família demorou de três a seis horas para procurar atendimento, o que pode ter contribuído para a complicação.

A falta de identificação do agente causal pode dificultar a escolha da conduta a ser adotada. A administração de SAAr em 98,87\% dos casos em que foi informado o tipo utilizado, se mostrou satisfatória, haja vista o elevado índice de cura. O MS recomenda que em casos considerados leves não há necessidade de uso de soro. ${ }^{12}$ No entanto, conforme os dados coletados, independente da gravidade do acidente, o SAAr foi administrado como parte do tratamento, sem levar em consideração o quadro clínico do paciente. Fica claro também, em muitos casos, o número errôneo de ampolas necessárias para cada gravidade e a falta de especificação do tipo de soro utilizado. Considerando que o acidente tenha sido por aranhas do gênero Phoneutria ou Loxosceles (mais comuns para região Centro Oeste) seria recomendada a administração de apenas duas a quatro ou cinco ampolas para o acidente moderado, e cinco a 10 ou 10 para o grave, respectivamente, de acordo com a aranha e o quadro clínico do paciente. ${ }^{10}$ Diante ao exposto, sugere-se que houve falta de observação aos sinais e sintomas antes de iniciar o tratamento.

A maioria dos casos de acidentes com aranhas evoluiu para a cura, concordando com o estudo de Silva, ${ }^{16}$ no qual $82,30 \%$ dos acidentados também tiveram boa evolução, mostrando que o prognóstico desses acidentes é geralmente bom e os óbitos são raros, o que corrobora também com o manual do MS. ${ }^{12}$

Os agentes causadores não foram citados nas fichas de notificações analisadas, o que configura uma limitação do estudo. Essa lacuna pode ser devida ao desconhecimento dos gêneros de aranhas por parte tanto dos acidentados quanto dos agentes notificadores, ou pelo preenchimento incompleto e inadequado das fichas de notificação compulsória. De acordo com as características do quadro clínico e da evolução do araneísmo presente em todos os dados analisados, não foi possível a identificação de acidente com o gênero Loxosceles no estado de Goiás. Não houve relato de dermonecrose no local da picada, tampouco evolução do quadro clínico para uma coagulopatia, como a coagulação intravascular disseminada, que culminaria em estado de instabilidade hemodinâmica e consequente aumento da taxa de morbimortalidade. Não foram descritos na literatura acidentes com esse gênero no estado de Goiás. Os seus locais de prevalência são a região Sul e Sudeste do país (estados do Paraná, Santa Catarina e São Paulo). ${ }^{13}$

São possíveis, embora não identificados, acidentes com Phoneutria no estado de Goiás, pois a espécie $P$. nigriventer é comum nos estados de Goiás, Mato Grosso do Sul, Minas Gerais, Paraná, Rio de Janeiro, Rio Grande do Sul, São Paulo e Santa Catarina. ${ }^{13}$ Alguns casos entre os identificados neste estudo apresentaram semelhança com o araneísmo causado pelo gênero Phoneutria, que tem como característica a agressividade e consequente atitude ao ataque, fazendo com que sua picada ocorra principalmente em mãos, braços e pernas, este último local o de maior prevalência dos acidentes ocorridos no Estado de Goiás. Para Chenet et al., ${ }^{13}$ o gênero encontrase em área domiciliar e peridomiciliar. $\mathrm{O}$ quadro clínico raramente evolui para gravidade, podendo levar, mais comumente, a algumas manifestações sistêmicas, como as vagais, relatadas nos casos analisados.

Ainda segundo Chenet et al., ${ }^{13}$ as aranhas do gênero Lycosa são relatadas com frequência, porém não constituem problema de saúde pública, pois seu veneno é pouco ativo para o ser humano, não necessitando de cuidados médicos. Esses acidentes também podem se responsabilizar pelos casos leves com sintomas locais que passam relativamente rápido, necessitando, algumas vezes, somente de bloqueio anestésico.

Os resultados deste estudo indicam que a prevalência do araneísmo está ligada ao processo de expansão urbana. O tratamento foi em geral satisfatório, com alto índice de cura e inexistência de óbitos. Entretanto, houve uso desnecessário de soro e de um número incorreto de ampolas em muitos casos. Este fato, além da ocorrência de dados ignorados ou não informados, sugere um distanciamento das recomendações do MS, que possui protocolos claros, desde a identificação da aranha até o uso de soro conforme a gravidade do caso. 


\section{REFERÊNCIAS}

1. Brazil TK, Leite CM, Pinto LMA, Silva RL, Brescovit A. Aranhas de importância médica do Estado da Bahia, Brasil. Gaz Med Bahia. 2009;1(79):32-7.

2. SINAN. Sistema de Informação de Agravo de Notificação. Acidentes por Animais Peçonhentos [Internet]. Brasília; 2013 [acesso em 15 jan 2013]. Disponível em: http://dtr2004.saude.gov.br/sinanweb/index.php

3. Fonseca GAB, Kent J, Mittermeier CG, Myers N. Biodiversity hotspots for conservation priorities. Nature. 2000;403:853-8.

4. Lobo J, Sastre P. Taxonomist survey biases and the unveiling of biodiversity patterns. Biol Conserv. 2009;142(2):462-7.

5. Castro AP, Silva TC, Silva JCR. Ocorrência, controle e prevenção de aranhas e escorpiões no nordeste brasileiro. 2009 [acesso em 20 mar 2014]. Disponível em: http:// http://www.eventosufrpe.com.br/jepex2009/cd/resumos/R0947-1.pdf

6. Fiszon JT, Bochner R. Subnotificação de acidentes por animais peçonhentos registrados pelo Sinan no Estado do Rio de Janeiro no período 2001 a 2005. Rio de Janeiro: Rev Bras Epidemiol. 2008;1(11):114-27.

7. ESRI. International User Conference Proceedings [Internet]. 2013 [acesso em 25 mar 2013]. Disponível em: http://www.esri.com

8. IBGE. Instituto Brasileiro de Geografia e Estatísticas. Censo Demográfico [Internet]. 2014 [acesso em 15 fev 2014]. Disponível em: http://ces.ibge.gov.br/base-de-dados/metadados/ibge/censo-demografico

9. OPAS. Organização Pan-Americana da Saúde. Indicadores Básicos para a Saúde no Brasil: Conceitos e Aplicações. $2^{\mathrm{a}}$ ed. Brasília; 2008.

10. Brasil. Ministério da Saúde. Guia de Vigilância Epidemiológica, Caderno 14 - Acidentes por Animais Peçonhentos. Brasília; 2009.

11. Chagas F, D’Agostini B, Betrame V. Aspectos Epidemiológicos dos Acidentes por Aranhas no Estado do Rio Grande do Sul. Joaçaba. Evidência. 2010;1-2(10):121-30.

12. Lucas SM. Aranhas de interesse médico no Brasil. $2^{\mathrm{a}}$ ed. São Paulo: Sarvier; 2009.

13. Chenet DC, Wolfart SC, Ferruzi P, Quadros RM, Marques SMT. Incidência de Aranhas de Importância em Saúde Pública em Curitibanos, Santa Catarina. Porto Alegre: Ciên Saúde. 2009;1(2):25-9.

14. Coutinho SED, Garcia FRM, Lise F. Características Clínicas do Araneísmo em Crianças e Adolescentes no Município de Chapecó, Estado de Santa Catarina, Brasil. Maringá: Acta Sci Health Sci. 2006;1(28):13-6.

15. Andrade NS, Martins FJ, Vieira RCPA, Vieira AAP, Raposo NRB. Perfil dos acidentes causados por aranhas na área de abrangência sanitária do município de Juiz de Fora- MG. Rev APS. 2011;14(3):303-12.

16. Silva EM. Loxoscelismo no Estado do Paraná: análise epidemiológica dos acidentes causados por Loxosceles Heinecken \& Lowe, 1832 no período de 1993 a 2000. Escola Nacional de Saúde Pública. Rio de Janeiro: Fundação Oswaldo Cruz; 2002. 